\title{
Product Transportation System Model Design of Category IV Gamma Irradiator Using Object Oriented Simulation
}

\author{
Fatin Yuniarti*, Adi Abimanyu, Hartomo Soewardi \\ Electro Mechanic Study Program, Department of Nuclear Technophysics, Polytechnic Institute of Nuclear \\ Technology, Yogyakarta, Indonesia \\ *Corresponding author: fatinyuniarti06@gmail.com
}

\begin{abstract}
The product transportation system of Gamma Irradiator: Category IV has not worked optimally. It is indicated by not being fulfilled a need of market demand as much 60,337 tons per year which the production supplied only $50 \%$ of necessity. This condition identified is caused by the ineffective product transportation system of Gamma Irradiator. Thus study is required to improve the system. Objective of this study is to redesign product transportation system of Gamma Irradiator: Category IV to improve the effectiveness of operation time. The method used is the Object Oriented Simulation with FlexSim application software. Simulations was carried out in computer laboratories with 3 types of products, namely Product A with $5 \mathrm{kGy}$ of dosage, Product B with $10 \mathrm{kGy}$ of dosage and Product $\mathrm{C}$ with $20 \mathrm{kGy}$ of dosage. Statistical analysis is conducted to validate the model developed by using Mann-Whitney Method. The result of this study shows that the proposed model is more effective at $5 \%$ of significance level where the first alternative is $0.35 \% ; 0.30 \%$; and $0.23 \%$ of effectiveness and the second alternative is $0.29 \% ; 0.25 \%$; and $0.18 \%$ of effectiveness for Product A, Product B, and Product $\mathrm{C}$ respectively.
\end{abstract}

Key words :transportation system, gamma irradiator, simulation model, flexsim, optimization.

\section{INTRODUCTION}

Irradiator is a nuclear installation that is used in the process of preservation of a product such as agricultural products and processed products, sterilization of medical devices and others. According to the International Atomic Energy Agency [1], irradiators are generally divided into two types, namely self-contained irradiator (category I and III) and panoramic irradiator (category II and IV) which category II is dry storage and category IV is wet storage.

Irradiator technology has not been widely used in Indonesia even though its application is useful in a very diverse industrial world, such as for the sterilization of medical equipment, medicines, food preservation, agricultural products and process. However the fact is many companies requiring the irradiation services. It was indicated increasing in market demand.

According to the National Nuclear Energy Agency [2], at least 52 companies use irradiation services for 37.268 tons / year of products. But the irradiation service has only capable for 17500 tons / year of products. Thus there are 19768 tons / year that has not been served. It is caused by production process has not met the target. One of the main components that plays an important role in the irradiation process is a product transportation system consisting of several parts that are loading and unloading tote (box that transports the product to be irradiated), bunker feedback section, railway track, and irradiated passages in Gamma Irradiator: Category IV.

The Gamma Irradiator: Category IV has been equipped with an automated system and also operated manually especially at the loading and unloading activities which it were carried out by the helper. This causes the longer preparation times such that affecting the overall processing time. Therefore it is crucial to improve the transportation system in Gamma Irradiator: Category IV in order to be more effective and efficient.

The objective of this study is to redesign the product transportation system in Gamma irradiator: Category IV to improve effectiveness and efficiency of the production process by using object oriented simulation.

\section{THEORYTICAL REVIEW}

\subsection{Irradiator}

Irradiators are equipment with sources of gamma transmitter radionuclides or X-ray generator accelerator planes or electron beams, which are used for research, sterilization and preservation of food ingredients.

\subsection{Category IV Gamma Irradiator}

A panoramic wet source storage irradiator (Category IV Gamma Irradiator) is a irradiator facility that controlled by human access, when not in use the radioactive source is fully shielded and stored in a pool of water. During operation, the source is exposed within a radiation room that is kept inaccessible by means of an entry control system [3]. 
The Category IV Irradiator facility has several main parts as shown in Figure 1. Unloading and loading as a place to remove and insert material to be irradiated into the carrier (tote). The part is outside the irradiation room, so the operator or employee can safely carry out the loading / unloading process without the need to think about the risk of radiation. Hanging Conveyor is used to carry material into the irradiation chamber. Aside from the picture, this conveyor system can also use rail track where the tote will be moved like a train to enter the irradiation chamber [4].

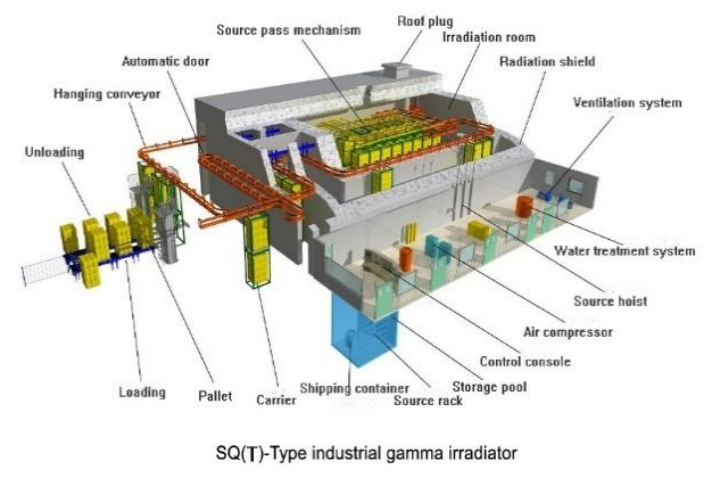

Figure 1: Category IV Gamma Irradiator

The mechanism of the irradiation process in category IV irradiator facilities are as follows: the radiation source wrapped in Category IV Gamma Irradiator is stored in the pond safely if not in use. The irradiation room is confined by a concrete wall with special specifications. The radiation source will be lifted up from the pond to irradiate the product. After the product has been irradiated, the radiation source will return to its storage area in the pond. Pond water serves as a radiation barrier [4].

\section{RESEARCH METHOD}

\subsection{Survey}

The survey was conducted to determine some parameters of the actual work process of the transportation system of the Category IV Gamma Irradiator.

\subsection{Measurement of Product Irradiaton Time}

Product irradiation time was determined by calculation with dose rate information from survey. These data determined by these criteria :

Product A dose : $5 \mathrm{kGy}$

Product B dose : 10kGy

Product $\mathrm{C}$ dose : $20 \mathrm{kGy}$

Dose rate at 1 Mei 2019: 1,2 kGy/hour

\subsection{Design and Simulation}

The simulation model design made using FlexSim 19.0.2 software. Simulation is a technique that mimics the processes that occur on a computer-assisted system and is based on certain assumptions. Simulation is the most widely used operational research and management method [5].
FlexSim is not the same as other simulation software [6]. FlexSim has advanced simulation technology features that are flexibility, easy to use, and 3-dimensional graphics [7].

\subsection{Develop an Alternative Model}

The validated model is then optimized by creating alternative model scenarios. This alternative model is made by changing the parameters contained in the model. The results of this alternative model must be more effective than the results of the initial model.

\subsection{Validation of the Model}

In this study the validation were carried out in 2 ways. The first validation of the simulation model purpose was to ensure the model can represent the real system or not. This validation used the Mann-Whitney statistical test to validate the data between the actual data and the simulation result. The simulation data used for the validation process are the Product A, Product B, and Product C. The chosen Confidence Level $(\alpha)$ is 0.05 . The equation is shown by equation (1) and (2) [8].

$$
\begin{aligned}
& \mathrm{U}_{1}=\mathrm{n}_{1} \mathrm{n}_{2}+\frac{n 1(n 1+1)}{2}-\mathrm{R}_{1} \\
& \mathrm{U}_{2}=\mathrm{n}_{1} \mathrm{n}_{2}+\frac{n 2(n 2+1)}{2}-\mathrm{R}_{2}
\end{aligned}
$$

The second validation purpose was to prove that there are significant changes that have been produced by alternative models compared to the initial model. This validation used $\mathrm{T}$-Test dependent sample test to see the resulting changes. The equation is shown by equation (3) [8].

$$
t_{\text {test }}=\frac{\overline{\mathrm{d}}-\mu_{\mathrm{d}}}{\frac{s_{\mathrm{d}}}{\sqrt{\mathrm{n}}}}
$$

\section{RESULT AND DISCUSSION}

Based on the survey, the flow of the product transportation process at the category IV gamma irradiator is divided into 3 stages, namely the pre-process, process and post-process. But before the pre-process starts, there is a setup process, namely the arrival of trucks carrying products to be irradiated and the products are transferred to the unirradiated area by the Forklift. Likewise after post-process, there is a process of transporting products from the irradiated area to trucks that will carry products by forklifts. But because it has been assumed that the products to be irradiated have been available in the unirradiated area and the products that have been irradiated have stopped in the irradiated area, this stage does not enter the simulation model.

Pre-process starts from transporting the product to be irradiated from the unirradiated area to the loading area by Forklift 1. Forklifts transport 16 products in 1 trip. Then the products will be filled by operator 1 into the tote. 1 tote is filled with 2 unirradiated products. Furthermore, the tote that has been filled will be pushed forward by operator 2 to be prepared to enter the Source Pass Mechanism. With the 
limitation of pneumatic system problems replaced by delay time, after the delay time is complete, the tote containing the unirradiated product will enter the Source Pass Mechanism via the Railway Track. This Railway Track Speed is the same as the Railway Track distance divided by 1 irradiation time at 1 step in the Source Pass Mechanism. So when there is one tote carrying an irradiated product out of the Source Pass Mechanism, at the same time there is one tote carrying the unirradiated product into the Source Pass Mechanism. After tote through the Railway Track, tote will enter the Source Pass Mechanism and the product irradiation process will begin. In the Source Pass Mechanism tote will go through the displacement path. In the Source Pass Mechanism it consists of 2 floors that are connected by elevator up and elevator down.

In the Source Pass Mechanism there are 72 steps for transferring the tote starting from the first tote into the Source Pass Mechanism until the last step is the 72nd step. The tote will enter and occupy the first step and will stop for the specified time according to the required dose.

After the tote completes stage 72 , the tote will be driven by pneumatic to the right and the tote carrying the irradiated product will come out of the Source Pass Mechanism and enter the Railway Track. At the same time the tote containing the new unirradiated product will enter the Railway Track to the Source Pass Mechanism. When the tote carrying the irradiated product came out of the Railway Track, the tote would be pushed to the left by pneumatics which had been replaced by delay time. Then by operator 3 tote is pushed towards operator 4 . Then by operator 4 irradiated product is excluded from tote and placed in unloading area. The tote that has been unloaded will be pulled by operator 5 to the right to be re-filled by a new unirradiated product. After there are 16 irradiated products in the unloading area, the Forklift will begin to transport and move the irradiated product to the irradiated area.

From the whole process, its known that the disadvantage is some process still had done manually by the operators. It is necessary to improve this in order to make system works more efficient. The parameter that used was the total time process which is influenced by the product irradiation time and the resources operation time. The resources are Operator 1, Operator 2, Operator 3, Operator 4, Operator 5, Transporter 1 and Transporter 2 .

\subsection{Initial Model}

Figure 2 and Figure 3 show 3D visualization of the Category IV Gamma Irradiator product transportation system simulation model. Based on the criteria we can calculate the irradiation time of each product and get the irradiation time of product as shown in Table 1. The actual data was included in the model by using Beta, Weibull, and Johnson Bounded distribution.

Table 1: Product Irradiation Time

\begin{tabular}{|c|c|}
\hline Type of Product & Irradiation Time (Hour) \\
\hline A & 4.17 \\
\hline B & 8.33 \\
\hline C & 16.67 \\
\hline
\end{tabular}

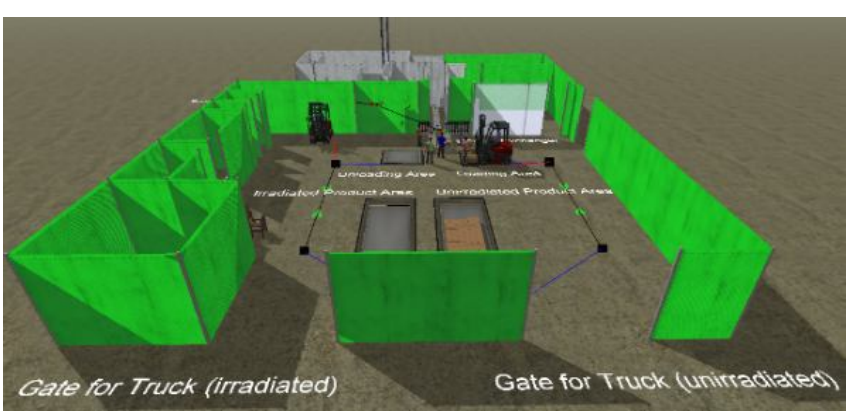

Figure 2: Overall model front view

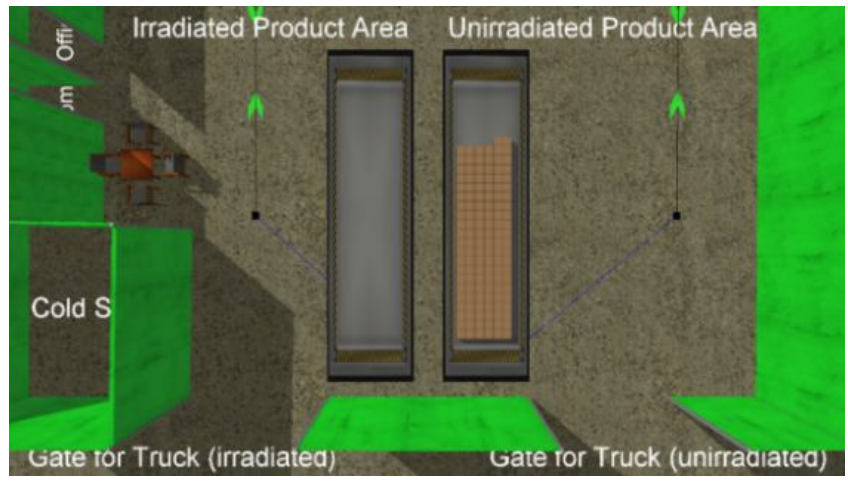

Figure 3: 3D Shape of unirradiated product

Table 2, Table 3, Table 4 show the calculation result of the Mann-Whitney test for comparison between Actual Data and Simulation Results of Product A, Product B and Product C.

Table 2: Statistic results of mann-whitney test between actual data and product A simulation model

\begin{tabular}{|c|c|c|c|c|c|c|c|}
\hline & $\begin{array}{c}\text { Operator 1 } \\
(\mathbf{s})\end{array}$ & $\begin{array}{c}\text { Operator 2 } \\
(\mathbf{s})\end{array}$ & $\begin{array}{c}\text { Operator 3 } \\
(\mathbf{s})\end{array}$ & $\begin{array}{c}\text { Operator 4 } \\
(\mathbf{s})\end{array}$ & $\begin{array}{c}\text { Operator 5 } \\
(\mathbf{s})\end{array}$ & $\begin{array}{c}\text { Transporter 1 } \\
(\mathbf{s})\end{array}$ & $\begin{array}{c}\text { Transporter 2 } \\
(\mathbf{s})\end{array}$ \\
\hline $\begin{array}{c}\text { Mann-Whitney } \\
\text { U }\end{array}$ & 1896.000 & 937.000 & 1152.000 & 2252.500 & 969.000 & 607.500 & 1136.500 \\
\hline Wilcoxon W & 1951.000 & 992.000 & 42768.000 & 2307.500 & 1024.000 & 662.500 & 27471.500 \\
\hline Z & -1.854 & -1.878 & -1.075 & -1.182 & -1.758 & -0.825 & -0.040 \\
\hline $\begin{array}{c}\text { Asymp. Sig. } \\
\text { (2-tailed) }\end{array}$ & 0.064 & 0.060 & 0.282 & 0.237 & 0.079 & 0.409 & 0.968 \\
\hline
\end{tabular}


FatinYuniarti et al., International Journal of Emerging Trends in Engineering Research, 8(7), July 2020,4834 - 4839

Table 3: Statistic results of mann-whitney test between actual data and product B simulation model

\begin{tabular}{|l|c|c|c|c|c|c|c|}
\hline & $\begin{array}{c}\text { Operator 1 } \\
(\mathbf{s})\end{array}$ & $\begin{array}{c}\text { Operator 2 } \\
(\mathbf{s})\end{array}$ & $\begin{array}{c}\text { Operator 3 } \\
(\mathbf{s})\end{array}$ & $\begin{array}{c}\text { Operator 4 } \\
(\mathbf{s})\end{array}$ & $\begin{array}{c}\text { Operator 5 } \\
(\mathbf{s})\end{array}$ & $\begin{array}{c}\text { Transporter 1 } \\
(\mathbf{s})\end{array}$ & $\begin{array}{c}\text { Transporter 2 } \\
(\mathbf{s})\end{array}$ \\
\hline $\begin{array}{l}\text { Mann-Whitney } \\
\mathrm{U}\end{array}$ & 793.000 & 392.000 & 483.000 & 879.500 & 714.000 & 220.500 & 534.500 \\
\hline Wilcoxon W & 848.000 & 447.000 & 538.000 & 934.500 & 11154.00 & 275.500 & 589.500 \\
\hline Z & -1.104 & -1.164 & -1.738 & -0.643 & -0.044 & -0.401 & -0.369 \\
\hline $\begin{array}{l}\text { Asymp. Sig. } \\
\text { (2-tailed) }\end{array}$ & 0.270 & 0.244 & 0.082 & 0.520 & 0.965 & 0.688 & 0.712 \\
\hline
\end{tabular}

Table 4: Statistic results of mann-whitney test between actual data and product $\mathrm{C}$ simulation model

\begin{tabular}{|l|c|c|c|c|c|c|c|}
\hline & Operator 1 (s) & Operator 2 (s) & Operator 3 (s) & Operator 4 (s) & Operator 5 (s) & Transporter 1 (s) & Transporter 2 (s) \\
\hline $\begin{array}{l}\text { Mann-Whitney } \\
\text { U }\end{array}$ & 431.000 & 144.000 & 288.000 & 447.000 & 336.000 & 87.000 & 222.000 \\
\hline Wilcoxon W & 486.000 & 1320.000 & 2916.000 & 502.000 & 391.000 & 142.000 & -0.573 \\
\hline Z & -0.430 & -1.977 & -1.021 & -0.254 & -0.340 & -1.178 \\
\hline $\begin{array}{l}\text { Asymp. Sig. } \\
(2-t a i l e d)\end{array}$ & 0.667 & 0.048 & 0.307 & 0.800 & 0.734 & 0.567 & 0.239 \\
\hline
\end{tabular}

Based on the Mann-Whitney test, we can analyze the results of $\mathrm{Z}$ and $\mathrm{P}$ value. $\mathrm{H}_{0}$ were received and there were no significant differences if the value of $\mathrm{Z}$ was smaller than $\mathrm{Z}_{\alpha / 2}$ and the $\mathrm{P}$ value was greater than the value of $\alpha$. For product $A$ the $\mathrm{Z}$ value operator 1 is obtained, operator 2 , operator 3 , operator 4 , operator 5 , transporter 1 , and transporter 2 are $-1.854 ;-1.878 ;-1.075 ;-1.182 ;-1.758 ;-0.825 ;-0.040$ and $\mathrm{P}$ value are $0.064 ; 0.60 ; 0.282 ; 0.237 ; 0.079 ; 0.409 ; 0.968$ respectively. Furthermore for Product B, based on the Mann-Whitney test, the $\mathrm{Z}$ value of operator 1 , operator 2, operator 3 , operator 4 , operator 5 , transporter 1 , and transporter 2 are $-1.104 ;-1.164 ;-1.738 ;-0.643 ;-0.044$; $-0.401 ;-0.369$ and $\mathrm{P}$ value $0.270 ; 0.244 ; 0.082 ; 0.520 ; 0.965$; $0.688 ; 0.712$ respectively.

Then for Product C, based on the Mann-Whitney test obtained the $\mathrm{Z}$ value operator 1 , operator 2 , operator 3 , operator 4 , operator 5 , transporter 1 , and transporter 2 are $0.430 ;-1.977$; $-1.021 ;-0.254 ;-0.340 ;-0.573 ;-1.178$ and $\mathrm{P}$ value 0.667 ; $0.048 ; 0.307 ; 0.800 ; 0.734 ; 0.567 ; 0.239$ respectively. The $\mathrm{P}$ value on all Mann-Whitney test results of Product A, Product $\mathrm{B}$ and $\mathrm{C}$ products has a $\mathrm{P}$ value greater than 0.05 and $\mathrm{Z}$ value is smaller than 1.96. So, this result shows that there is no significant difference between the actual data and the simulation data. Based on these conclusions, product $\mathrm{A}$, product $\mathrm{B}$ and product $\mathrm{C}$ models can be declared valid and can be used for further development to solve the current problem.

\subsection{Proposed Model}

In order to improve the system, the simulation model have been developed. Figure 4 and Figure 5 show 3D visualization of the proposed simulation model. There are 2 alternatives model proposed. Both alternatives have some improvements, which are the removal of loading and unloading areas and reduction of conveyor length in storage exchangers. Alternative 1 replaced the operator performance with the robotic arms while the alternative 2 reduced the number of the operators. These improvements shown in Figure 4 and Figure 5 for alternative 1 while alternative 2 shown by Figure 6 and Figure 7.

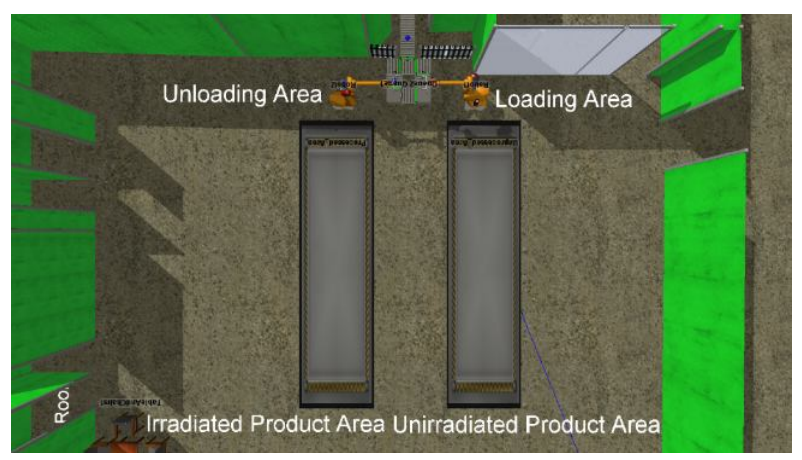

Figure 4: Overall model front viewof alternative 1

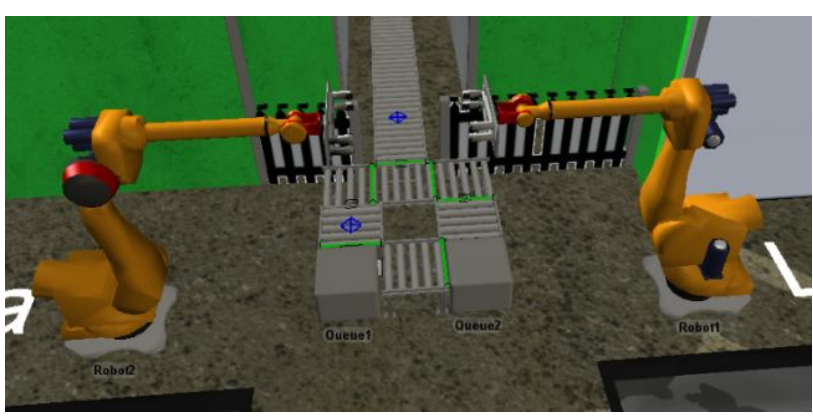

Figure 5: 3D Shape alternative 1 optimization results

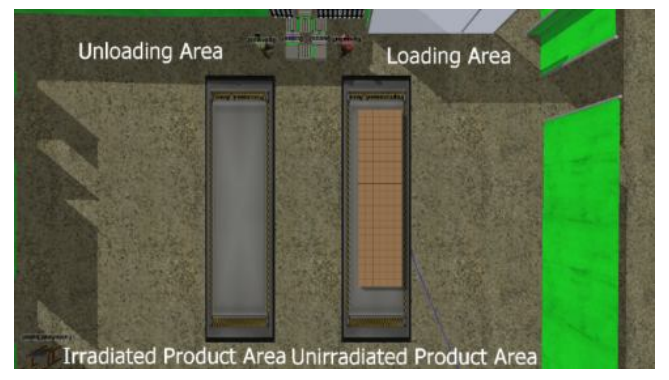

Figure 6: Overall model front viewof alternative 2 Table 4 shows the results of the T-Test 2 dependent samples. Output Table 4 contains information about the value of the total alternative time difference between the two alternatives, amounting to 273.66 for pair 1 and 228.33 for pair 2. Based on 
Table 8 it is known that the Sig (2 Tailed) for both pairs are $0,000<0,05$. So that it can be concluded at the level of significance of $5 \%$ there is a difference in the average total time between the actual model and after optimization both with alternative 1 and with alternative 2 , which means the system becomes more effective.

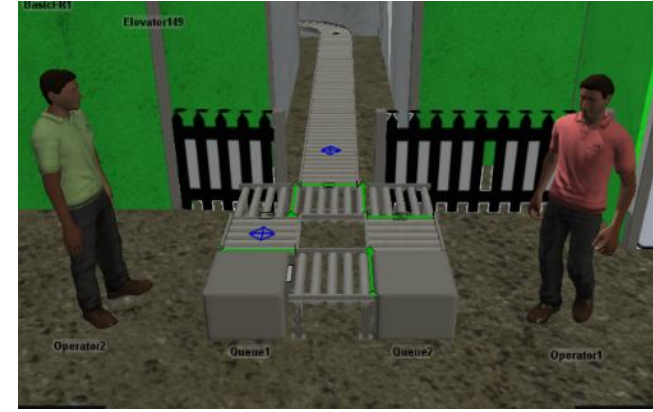

Figure 7: 3D Shape Alternative 2 Optimization Results

Table 4. Paired Samples Test Result

\begin{tabular}{|c|c|c|c|c|c|c|c|}
\hline Pair & & Mean & $\begin{array}{c}\text { Std. } \\
\text { Deviation }\end{array}$ & $\begin{array}{c}\text { Std. Error } \\
\text { Mean }\end{array}$ & t & df & $\begin{array}{c}\text { Sig. (2 } \\
\text { Tailed) }\end{array}$ \\
\hline 1 & $\begin{array}{c}\text { Model_Actual\& } \\
\text { Model_Alternative1 }\end{array}$ & 273.66 & 3.21 & 1.86 & 147.46 & 2 & 0.000 \\
\hline 2 & $\begin{array}{c}\text { Model_Actual\& } \\
\text { Model_Alternative2 }\end{array}$ & 228.33 & 6.11 & 3.53 & 64.73 & 2 & 0.000 \\
\hline
\end{tabular}

In addition to looking at the Sig (2 Tailed) value, the relationship between the two variables can be ascertained through a comparison of the $t$ count values with the $t$ value in the table. If the value of $t$ count $>t$ table then $\mathrm{H}_{0}$ is rejected or there is a significant difference between the actual and alternative model variables. For pair 1 the $t$ value is 147.46. With the value of $\mathrm{df}=2$ and $\alpha=0.05$, the value of $\mathrm{t}$ table is 2.92. For pair 2 , the value of $t$ is 64.73 . With the value of $\mathrm{df}=$ 2 and $\alpha=0.05$, the value of $t$ table is 2.92 . Because the value of $t$ count of the two pairs is greatest than the value of the $t$ table, it can be expressed with a level of significance of $5 \%$, there is a difference in the total time between the actual model and after optimization both with alternative 1 and with alternative 2, which means the system becomes more effective.

Based on the results of the T-Test 2 dependent samples that have been done, it can be seen that both alternatives can make the model more effective. Alternative 1 has the advantage of giving results that are more effective than alternatives 2 . Although this study does not consider economic aspects, alternative 1 has the disadvantage of changing the system that replaces operators with robots will require large costs or investments. Whereas alternative 2 has an excess cost or a cheaper investment but has a disadvantage that is not as effective a robot arm in the time of completion of the loading and unloading process. In addition, the reduction of operators will provide excessive workload for operators because the irradiation process continues.

Further reading for different application of transportation in another area can be found in [9] and [10].

\section{CONCLUSION}

It can be concluded as follow:

1. The alternative 1 of proposed design of the product transportation system has 76208 second of total time for the product A, 91214 second of total time for product B and 122013 second of total time for product $\mathrm{C}$.

2. The alternative 2 proposed model has valid with the total time 76251 second of total time for product A, 91255 second of total time for product B, 122065 second of total time for product $\mathrm{C}$.

3. The efficiency of alternative 1 are $0.35 \% ; 0.30 \%$; and $0.23 \%$ respectively while alternative 2 are $0.29 \%$; $0.25 \% ; 0.18 \%$ respectively.

It is known that the proposed design of alternative 1 is better than the proposed design of alternative 2 .

\section{REFERENCES}

1. International Atomic Energy Agency, 2015. Gamma Irradiators For Radiation Processing. Vienna.

2. National Nuclear Energy Agency, 2014. Irradiator Feasibility Study. National Nuclear Energy Agency.

3. International Atomic Energy Agency, 2010. Radiation Safety of Gamma, Electron and X Ray Irradiation Facilities.

4. National Nuclear Energy Agency Education and Training Center, 2015. Irradiator Safety System.

5. W. D. Kelton, A. N. Law. Simulation Modeling and Analysis, 3rd ed. New York: McGraw-Hill, 1991.

6. W. B. Nordgren. FlexSim Simulation Environment 4, 2003.

7. FlexSim, 2014. About Us - Flexsim Simulation Software. URL https://www.flexsim.com/company/ (accessed 6.12.18). 
8. Harinaldi.Statistical Principles for Engineering and Science. Jakarta: Erlangga, 2005.

9. Hussein, W.N., Kamarudin, L.M., Hamzah, M.R., Hussain, H.N., Jadaa, K.J.A methodology for big data analytics and IoT-oriented transportation system for future implementation, International Journal of Emerging Trends in Engineering Research 7(11),8, pp. 449-453, 2019.

https://doi.org/10.30534/ijeter/2019/087112019

10. Larioui, J., El Byed, A. Multi-agent system architecture oriented prometheus methodology design for multi-modal transportation, International Journal of Emerging Trends in Engineering Research 8(5), pp. 2118-2125, 2020.

https://doi.org/10.30534/ijeter/2020/105852020 